Article

\title{
Predicting Burnout Factors among Healthcare Providers at Private Hospitals in Saudi Arabia and United Arab Emirates: A Cross-Sectional Study
}

\author{
Awad Al-Omari ${ }^{1,2}$, Abbas Al Mutair ${ }^{1,2,3,4}\left(\mathbb{D}\right.$, Abbas Shamsan ${ }^{1}$ and Alya Al Mutairi ${ }^{5, *(D)}$ \\ 1 Research Center, Dr. Sulaiman Al Habib Medical Group, Riyadh 11372, Saudi Arabia; \\ awad.alomari@drsulaimanalhabib.com (A.A.-O.); abbas4080@hotmail.com (A.A.M.); \\ Abbasmanar.11@gmail.com (A.S.) \\ 2 College of Medicine, Alfaisal University, Riyadh 11643, Saudi Arabia \\ 3 College of Health Sciences, University of Sharjah, Sharjah 27272, UAE \\ 4 School of Nursing, Wollongong University, Wollongong NSW 2522, Australia \\ 5 Department of Mathematics, Faculty of Science, Taibah University, Medina 41521, Saudi Arabia \\ * Correspondence: amutairi@taibahu.edu.sa
}

Received: 14 November 2019; Accepted: 18 December 2019; Published: 24 December 2019

\begin{abstract}
Background: Burnout is defined as a long-term work stress. The prevalence of burnout syndrome among nurses is $42 \%$ of nurses in England. Many countries have conducted studies to measure the level of burnout among health care providers. There is a lack of research on burnout among healthcare providers in the Arabic countries. Aims: This study aimed to assess the burnout level among healthcare providers in Saudi Arabia and United Arab Emirates and to predict the burnout factors of healthcare providers working in tertiary private hospitals. Methods: A descriptive cross-sectional survey was used to evaluate the burnout among healthcare providers. A total of 900 healthcare providers working in the clinical areas of six private hospitals in the Arabia Gulf Region were recruited for the study. A total of 892 healthcare providers were included in the study. A total of eight surveys were excluded due to major missing data. Results: A total of 892 healthcare providers were included in the study. The average age was 32 years \pm 7 years for male and female healthcare providers. A high burnout level was found in the results. The participating female healthcare providers had a higher level of emotional exhaustion as compared with their male counterparts. Nurses had more emotional exhaustion as compared with physicians, respiratory therapists, and other colleagues. Conclusions: High burnout levels among healthcare providers can reflect negatively on the healthcare providers well-being, job satisfaction, and mental health. Burnout has been linked with medical errors and physician-patient relationships. We believe that it is important to deal with this issue of public health in Saudi Arabia and UAE. This study aimed to explore burnout levels among healthcare providers in Saudi Arabia and UAE. Results showed a high level of burnout among the healthcare.
\end{abstract}

Keywords: burnout; Maslach Burnout Inventory; healthcare providers; private hospitals; Saudi Arabia; UAE

\section{Background}

Burnout syndrome is a state of psychological, emotional, and physical stress that results from work-related stressors [1]. High turnover rate, absences, injuries, and medical errors are comorbid characteristics with burnout syndrome [2]. The literature has shown that healthcare providers are more vulnerable to burnout syndrome [3]. The prevalence rate of burnout among medical, radiation, and surgical oncologists is $35 \%$ [4]. There are several etiologies for burnout. Heavy workload, working 
without meaning, loss of autonomy, and having less time flexibility are all factors that cause burnout syndrome [4]. A study in the US found that among 7288 physicians, $45.8 \%$ doctors had experienced some symptoms of burnout syndrome. The highest rates for experiencing burnout symptoms were among the family and emergency doctors [5]. There is a significant relationship between medical errors and burnout. In the US, around $9 \%$ of 8000 surgeons reported that they made medical errors. Burnout has been found associated with substance abuse, lack of motivation, and performance, which can lead to medical errors [6,7]. There are many factors for job dissatisfaction among inpatient nurses such as dealing with death cases and a stressful work environment [8]. Burnout is defined as a long-term work stress. Reports show that $42 \%$ of nurses in England are suffering from burnout; in Greece $44 \%$ of nurses reported that they were not satisfied with their job, and they would prefer to leave their work. A study was conducted in Brazil, and they found that $10 \%$ of the nurses had burnout, and more than $50 \%$ had the potential for the syndrome [9]. Burnout among healthcare providers in the Arab World has been found moderate to high. Anxiety, irritability, mood swings, insomnia, depression, and a sense of failure are presented as consequences of burnout [10]. In this study, we aim to explore the factors of burnout among private healthcare providers in Saudi Arabia using Maslach Burnout inventory.

\section{Study Purpose}

The purpose of the study was to assess the burnout level among healthcare providers in Saudi Arabia and United Arab Emirates and to predict the burnout factors of healthcare providers.

\section{Design}

A descriptive cross-sectional design survey was used to evaluate the burnout among healthcare providers. The study was performed on 892 healthcare providers working in the clinical areas of six private hospitals in the Arabia Gulf Region. A convenience sampling techniques was used to recruit healthcare providers from different hospitals. A minimum sample size of 630 participants was chosen to allow estimation of moderate effect size at $5 \%$ significant level with $80 \%$ power. The data collection instrument included two parts, sociodemographic and the Maslach Burnout Inventory MBI. In the sociodemographic part, participants were asked to indicate their age, gender, marital status, profession, nationality, and years of experience. The MBI measures the severity of burnout by asking the respondents to indicate on a seven-point Likert Scale which was developed by Maslach et al. (1996) [11]. The MBI consisted of 22 items and considered three dimensions as follows: emotional exhaustion, nine items; accomplishment eight items, and depersonalization, five items. Emotional exhaustion has to do with a healthcare provider's feelings of being emotionally exhausted by the work. Personal accomplishment has to do with a healthcare providers' feelings of success in work. Depersonalization has to do with a healthcare provider's response of one's service. The data collection instruments were distributed in the English language.

MBI has been used extensively in many international studies in different geographical areas. The results have shown excellent coefficient reliability, for example, the alpha coefficients were 0.83 for emotional exhaustion, 0.79 for depersonalization, and 0.74 for personal accomplishment [12]. Additionally, similar results have been found for numerous smaller studies of numerous samples recruited from different locations $[13,14]$. Scores of each subscale is calculated by adding up all scores of all items in the subscale. Burnout is expressed by all scores of the three subscales. Emotional exhaustion and depersonalization are positive statements while personal accomplishments are negative statements. In positive statements, higher scores indicate higher levels of burnout, whereas, in negative statements, lower scores indicate higher levels of burnout. Scores range from 0 to 36 for emotional exhaustion, from 0 to 20 for depersonalization, and from 0 to 32 for personal accomplishment subscale. A total of 1150 questionnaires were sent out to five private hospitals in Saudi Arabia and one private hospital in the UAE, 900 were returned, with a response rate of $78.2 \%$ and eight questionnaires with missing data were excluded. There was a total of 892 questionnaires in the analysis. 


\section{Ethical Considerations}

Prior to data collection, the study obtained an IRB approval from Dr. Sulaiman Al Habib Medical Group (RC18.11.21) to conduct the study. All participants were fully informed of the nature of the study, risks and benefits, and were ensured that their participation in the study was voluntary and confidential and that they did not have to include their name.

\section{Data Analysis}

The questionnaires' data were entered into an excel spreadsheet and, then, were imported into Statistical Package for Social Sciences SPSS version 24 for windows. Descriptive and inferential analysis were performed using SPSS. Descriptive statistics were employed using percentage and means to analyze the participants' demographic profiles and burnout occurrence. Parametric and non-parametric methods including $t$. test, ANOVA, Mann-Whitney U test, and Kruskall-Wallis were performed based on normality, of distribution, as the sampling distributions were sometimes found irregular. In addition, Spearman Correlation tests were used between numerical data to detect the nature of the relationship.

\section{Results}

The age of the participating healthcare providers in the study ranged from 21 to 63 years with an average of 32 years \pm 7 years. Female healthcare providers compromised $73 \%$ (655) of the participants and $231(26.1 \%)$ were men. Married healthcare providers accounted for 381 (43.7\%), while, $477(54.7 \%)$ were single, and 14 (1.6\%) were divorced. The sociodemographic characteristics of the participating healthcare providers are summarized in Table 1 . The healthcare providers were recruited from six private hospitals in Saudi Arabia and United Arab Emirates. The vast majority of the participating healthcare providers were nurses $616(69.8 \%)$, physicians $115(12.8 \%)$, and only $18(2 \%)$ were respiratory therapists, while, 134 (15.2\%) of the total sample were other healthcare providers.

Table 1. Sociodemographic characteristics of participants $(n=892)$.

\begin{tabular}{ccc}
\hline Characteristics & Subgroups & Frequency (\%) \\
\hline \multirow{2}{*}{ Age } & Median $(I Q R)$ & 32 years \pm 7 years \\
& Max & 63 years \\
Min & 21 years \\
\hline \multirow{2}{*}{ Gender } & Male & $231(26.1 \%)$ \\
& Female & $655(73 \%)$ \\
& Missing & 12 \\
\hline \multirow{3}{*}{ Marital status } & Single & $477(54.7 \%)$ \\
& Married & $381(43.7 \%)$ \\
& Divorced & $14(1.6 \%)$ \\
& Missing & 26 \\
\hline \multirow{2}{*}{ Profession } & Physicians & $115(12.8 \%)$ \\
& Nurse & $616(69.8 \%)$ \\
& Respiratory Therapist & $18(2 \%)$ \\
& Others & $134(15.2 \%)$ \\
& Missing & 15 \\
\hline \multirow{2}{*}{ Nationality } & Saudi & $84(9.8 \%)$ \\
& Non-Saudi & $770(90.2 \%)$ \\
& Missing & 44 \\
\hline Years of experience & 1 to 5 years & $406(45.2 \%)$ \\
& 6 to 10 years & $338(37.6 \%)$ \\
& years and above & $130(14.5 \%)$ \\
& Missing & 24 \\
\hline
\end{tabular}


As indicated in Table 1, healthcare providers who participated in the current study were mainly non-Saudi $770(90.2 \%)$ and Saudi compromised $84(9.8 \%)$. Of the total, $406(45.2 \%)$ participants revealed that they had work experience between one to five years, $338(37.6 \%)$ six to ten years of working experience, and $130(14.5 \%)$ had 11 or more years of clinical experience.

Table 2 shows the results of the burnout dimensions among participating healthcare providers. Healthcare providers were at a high level of emotional exhaustion with $34.33 \pm 11$. 87 . With regards to personal accomplishment, the data analysis showed that healthcare providers had a high level of reduced personal accomplishment including beliefs of competence and successful achievement at work $32.67 \pm 8.01$. Participants also experienced high levels of depersonalization $12.92 \pm 7.03$.

Table 2. Overall mean of burnout dimensions $(n=892)$.

\begin{tabular}{cccc}
\hline Dimensions & Min & Max & Mean (SD) \\
\hline Emotional Exhaustion & 0 & 54.00 & $34.33(11.87)$ \\
\hline Personal Accomplishment & 0 & 48.00 & $32.67(8.01)$ \\
\hline Depersonalization & 0 & 30.00 & $12.92(7.03)$ \\
\hline
\end{tabular}

A correlation analysis between burnout dimensions among the participating healthcare providers was computed. The results demonstrated that there was a weak correlation between personal accomplishment and emotional exhaustion $(p \leq 0.0001, \mathrm{r}=0.20)$. A strong correlation was detected between emotional exhaustion and depersonalization $(p \leq 0.0001, \mathrm{r}=0.66)$ among healthcare providers. Analysis also revealed that there was a weak correlation between personal accomplishment and depersonalization dimension $(p \leq 0.0001, \mathrm{r}=0.23)$ as shown in Table 3.

Table 3. Correlation analysis between burnout dimensions $(n=892)$.

\begin{tabular}{|c|c|c|c|}
\hline Dimension & Emotional Exhaustion & Personal Accomplishment & Depersonalization \\
\hline $\begin{array}{c}\text { Emotional Exhaustior } \\
p \text { Value } \\
R \text { Value }\end{array}$ & & & \\
\hline $\begin{array}{c}\text { Personal } \\
\text { Accomplishment } \\
p \text { Value } \\
R \text { Value }\end{array}$ & $\begin{array}{c}\leq 0.0001 \\
0.2\end{array}$ & & \\
\hline $\begin{array}{c}\text { Depersonalization } \\
p \text { Value } \\
R \text { Value }\end{array}$ & $\begin{array}{c}\leq 0.0001 \\
0.66\end{array}$ & $\begin{array}{c}\leq 0.0001 \\
0.23\end{array}$ & \\
\hline
\end{tabular}

Inferential statistics were used to detect the relationship between sample demographics and burnout utilizing parametric and nonparametric methods. Inferential analysis showed that there was a statistically significant difference in the scores of emotional exhaustion dimension for male 31.73 (13.41) and female participants $35.28(11.11), t(855)=3.85, p \leq 0.0001$. The participating female healthcare providers had a higher level of emotional exhaustion than that of their male colleagues. There also was a statistically significant difference in the scores of emotional exhaustion for Saudi 31.30 (12.77) and non-Saudi $34.53(11.70), t(824)=5.98, p=0.01$. Non-Saudi healthcare providers had a higher level of emotional exhaustion than that of the Saudi healthcare providers.

An ANOVA test demonstrated that there was a statistically significant effect of profession on emotional exhaustion at the $p<0.05$ for the nurses $(F(3,852)=29.85, p \leq 0.0001)$. Nurses had more emotional exhaustion than that of their physicians, respiratory therapists and other colleagues. Nonetheless, there was a statistically significant effect of profession on personal accomplishment at $p<0.05$ for the nurses $(\mathrm{F}(3,853)=6.32, p \leq 0.0001$ (. Nurses had more reduced personal accomplishment 
than other healthcare providers and nurses scored higher on the depersonalization dimension. There was a statistically significant effect of profession on depersonalization at the $p<0.05$ for the nurses $(F(3,847)=13.69, p \leq 0.0001)$.

The marital status variable showed that it was a statistically significant factor of burnout among healthcare providers. There was a statistically significant effect of marital status on emotional exhaustion at $p<0.05$ for the married participants $(\mathrm{F}(2,841)=5.01, p=0.007)$ as married participants showed a higher burnout level. In addition, there was a statistically significant effect of marital status on depersonalization at the $p<0.05$ for the married participants $(\mathrm{F}(2,841)=7.83, p \leq 0.0001)$.

When an ANOVA test was performed, statistically significant results were detected between burnout dimensions and participants' years of experience. Burnout was higher in healthcare providers with one to 10 years of working experience.

As illustrated in Table 4, emotional exhaustion, personal accomplishment, and depersonalization were statistically and significantly higher; $p \leq 0.0001, p=0.01$, and $p=0.002$, respectively.

Table 4. Participants' sociodemographic and burnout dimensions means comparisons $(\mathrm{n}=892)$.

\begin{tabular}{|c|c|c|c|c|c|c|}
\hline \multirow{3}{*}{ Variables } & \multicolumn{6}{|c|}{ Burnout Dimensions } \\
\hline & \multicolumn{2}{|c|}{ EE } & \multicolumn{2}{|c|}{ PA } & \multicolumn{2}{|c|}{ Depersonalization } \\
\hline & \multicolumn{2}{|c|}{ M (SD) $p$ Value } & \multicolumn{2}{|c|}{ M (SD) $p$ Value } & \multicolumn{2}{|c|}{ M (SD) $p$ Value } \\
\hline \multicolumn{7}{|l|}{ Gender } \\
\hline Male & $31.73(13.41)$ & $p \leq 0.0001$ & $32.87(9.04)$ & $p=0.71$ & $12.87(7.73)$ & $p=0.92$ \\
\hline Female & $35.28(11.11)$ & & $32.64(7.63)$ & & $12.92(6.76)$ & \\
\hline \multicolumn{7}{|l|}{ Marital Status } \\
\hline Single & $33.14(11.76)$ & & $33.25(7.80)$ & & $12.15(7.11)$ & \\
\hline Married & $35.60(11.87)$ & $p=0.007$ & $31.95(8.03)$ & $p=0.06$ & $13.70(6.86)$ & $p \leq 0.0001$ \\
\hline Divorced & $37.57(11.91)$ & & $33.21(11.21)$ & & $17.35(6.69)$ & \\
\hline \multicolumn{7}{|l|}{ Profession } \\
\hline Physicians & $26.89(14.79)$ & & $35.60(7.98)$ & & $10.26(7.80)$ & \\
\hline Nurse & $36.65(10.30)$ & $p \leq 0.0001$ & $32.42(7.73)$ & $p \leq 0.0001$ & $13.91(6.64)$ & $p \leq 0.0001$ \\
\hline RT & $32.55(8.46)$ & & $34.00(6.54)$ & & $11.25(6.97)$ & \\
\hline Others & 30.46 (12.17) & & $31.52(8.59)$ & & $10.94(6.89)$ & \\
\hline \multicolumn{7}{|l|}{ Nationality } \\
\hline Saudi & $31.30(12.77)$ & $p=0.01$ & $32.09(9.13)$ & $p=0.51$ & $13.28(7.68)$ & $p=0.50$ \\
\hline Non-Saudi & $34.53(11.70)$ & & $32.69(7.83)$ & & $12.68(6.90)$ & \\
\hline \multicolumn{7}{|l|}{ Experience } \\
\hline 1 to $5 \mathrm{yrs}$ & $34.72(11.22)$ & & $32.08(7.75)$ & & $13.26(6.51)$ & \\
\hline 6 to $10 \mathrm{yrs}$ & $35.68(11.30)$ & $p \leq 0.0001$ & $32.82(7.89)$ & $p=0.01$ & $13.15(7.25)$ & $p=0.002$ \\
\hline 11 yrs and more & $30.01(13.70)$ & & 34.39 (8.41) & & $10.75(7.51)$ & \\
\hline
\end{tabular}

EE, emotional exhaustion; PA, personal accomplishment; RT, respiratory therapist.

\section{Discussion}

In this study, burnout factors were examined in a large sample of 892 healthcare providers in Saudi Arabia and UAE, and it was shown that healthcare providers had a high percentage of burnout. To our knowledge, there are few comprehensive studies on burnout among healthcare providers in both Saudi Arabia and UAE. The results show that the median age is 32 years old, the majority of the participants were female, and around $477(54.7 \%)$ were single. This is justified by the fact that the majority of the participants were nurses (69.8\%) and non-Saudi. Saudi Arabians recruit nurses from around the world, which justifies that most of the participants (i.e., $82.8 \%$ ) have fewer than 10 years of work experience.

In this study, a correlation analysis between the three burnout dimensions among the participating healthcare providers was calculated. There was a strong correlation between emotional exhaustion and depersonalization $(p \leq 0.0001, r=0.66)$ among healthcare providers. Previous studies have identified emotional exhaustion and depersonalization as the "core dimensions", and they have found similar 
results for the correlation analysis between the two dimensions $[15,16]$. Personal accomplishment was found to have a weak correlation with depersonalization and emotional exhaustion dimensions, unlike a previous study that found a positive correlation between emotional exhaustion and depersonalization, but a weak negative correlation between personal accomplishment and emotional exhaustion and depersonalization [16]. Several studies have reported results that are in agreement with this study, which is that females have higher emotional exhaustion than males [17-20]. In the United States, 6000 physicians participated in a burnout study; results showed that females were $60 \%$ more likely to have burnout syndrome than males [21]. Those findings can be related to the difference in salaries between females and males, lack of social support, and lack of resources.

In our study, married participants showed a higher level of emotional exhaustion and a low level of personal accomplishment. On the one hand, the literature has shown that several studies have suggested that being married or having been married show tendencies for higher levels of emotional exhaustion $[19,22,23]$. On the other hand, other studies have shown that single healthcare providers score higher burnout levels than married workers [20]. In addition, studies suggest that being unmarried has a lower level of personal accomplishment and a higher level of depersonalization [24]. Evidence supports that marital status is a significant factor for burnout, and the reason behind having a high level of emotional exhaustion (EE) in married and divorced workers is the work-home stress. In other words, healthcare providers could have difficulty in managing the time and balancing their time between the occupation and the family, especially, if there are children who can be stressors for the healthcare providers. Length of experience is a significant factor for burnout, and the results showed that healthcare providers who had higher years of experience were less likely to experience emotional exhaustion and depersonalization. Previous studies have shown that older nurses with more years of experience are experiencing burnout less than younger nurses [25]. In addition, older physicians have lower levels of burnout [26]. Some studies have shown opposite results to the results in this study; older physicians scored a higher level of emotional exhaustion [24]. The results of this study showed that there can be some logical reasons why more experienced healthcare providers have less emotional exhaustion and depersonalization levels which is the ability to cope with stress and time management. Healthcare providers, with fewer years of experience, have difficulty coping with stress and workload. In this study, results showed that nurses have higher burnout levels than physicians and respiratory therapists. The sample size of nurses was significantly larger than other professions, and around $90 \%$ of the participants were not Saudi citizens, which can imply that the factors of high burnout levels among nurses are adapting to living in Saudi Arabia, workload, and work environment.

The limitations of this study are several. It is a cross-sectional study that uses the MBI-HSS, and it is important to note that the MBI-HSS is a self-reported questionnaire. Hence, results rely heavily on the subjective perception of individuals instead of defined clinical diagnosis and objective methods. The sample used in the study was comprised mostly of non-Saudi females and nurses, and this could have impacted the results obtained. In addition, the research was performed on individuals practicing in the private sector only; hence, results cannot be generalized to the entire population. Burnout syndrome has become a common research interest internationally. Since there are few researches on burnout phenomena among healthcare providers in the Arab countries, this study aimed to examine burnout among healthcare providers in Saudi Arabia and UAE. Results showed high burnout levels among healthcare providers in both of the countries, which can reflect negatively on the healthcare providers' well-being, job satisfaction, and mental health. Burnout has been linked with medical errors, and the physician-patient relationships. We believe that it is important to deal with this issue for public health in Saudi Arabia and UAE.

\section{What Is Already Known about This Subject?}

- High burnout level among healthcare providers was found in literature review;

- There was a lack of research on burnout among healthcare provider at private hospitals in the Arab countries. 


\section{What This Study Adds?}

- High burnout level among Saudi and non-Saudi healthcare providers in Saudi Arabia;

- It is crucial to deal with the issue for public health in Saudi Arabia and UAE;

- Certain policies and guideline should be created to assess that healthcare providers are working with a healthy psychological state.

\section{What Impact This May Have on Practice or Policy?}

- If the burnout level is lower, job satisfaction will be higher which will impact on the turnover rates;

- Fewer medical errors;

- More beneficial patient care.

Author Contributions: Conceptualization, A.A.-O. and A.A.M.; methodology, A.A.M. and A.A.M.; formal analysis, A.A.M.; resources, A.S.; data curation, A.S.; writing-original draft preparation, A.A.M. and A.A.-O.; writing-review and editing, A.A.M. and A.A.M.; supervision, A.A.-O. and A.A.M.; All authors have read and agreed to the published version of the manuscript.

Funding: This research received no external funding.

Acknowledgments: The authors thank the referee for constructive comments.

Conflicts of Interest: The authors declare no conflict of interest in preparing this article

\section{References}

1. Maslach, C.; Schaufeli, W.B.; Leiter, M.P. Job Burnout. Annu. Rev. Psychol. 2001, 52, 397-422. [CrossRef] [PubMed]

2. Dyrbye, L.N.; Thomas, M.R.; Massie, F.S.; Power, D.V.; Eacker, A.; Harper, W.; Durning, S.; Moutier, C.; Szydlo, D.W.; Novotny, P.J. Burnout and Suicidal Ideation among U.S. Medical Students. Ann. Intern. Med. 2008, 149, 334. [CrossRef] [PubMed]

3. Elbarazi, I.; Loney, T.; Yousef, S.; Elias, A. Prevalence of and factors associated with burnout among health care professionals in Arab countries: A systematic review. BMC Health Serv. Res. 2017, 17. [CrossRef] [PubMed]

4. Shanafelt, T.; Dyrbye, L. Oncologist Burnout: Causes, Consequences, and Responses. J. Clin. Oncol. 2012, 30, 1235-1241. [CrossRef] [PubMed]

5. Lee, Y.; Medford, A.; Halim, A. Burnout in physicians. J. R. Coll. Physicians Edinb. 2015, 45, $104-107$. [CrossRef]

6. Gulalp, B.; Karcioglu, O.; Sari, A.; Koseoglu, Z. Burnout: Need help? J. Occup. Med. Toxicol. 2008,3 , 32. [CrossRef] [PubMed]

7. Makary, M.A.; Sexton, J.B.; Freischlag, J.A.; Holzmueller, C.G.; Millman, E.A.; Rowen, L.; Pronovost, P.J. Operating room teamwork among physicians and nurses: Teamwork in the eye of the beholder. J. Am. Coll. Surg. 2006, 202, 746-752. Available online: https://www.ncbi.nlm.nih.gov/pubmed/16648014 (accessed on 26 February 2019). [CrossRef]

8. Patricia Potter, R.N.; Joyce Divanbeigi RN, M.S.N.; Julie Berger DMin, B.C.C.; Lori Norris, R.N.; Sarah Olsen RN, B.S.N. Compassion fatigue and burnout: Prevalence among oncology nurses. Clin. J. Oncol. Nurs. 2010, 14, E56. Available online: https://www.ncbi.nlm.nih.gov/pubmed/20880809 (accessed on 26 February 2019). [CrossRef]

9. Ribeiro, V.F.; Ferreira Filho, C.; Valenti, V.E.; Ferreira, M.; de Abreu, L.C.; de Carvalho, T.D.; Xavier, V.; de Oliveira Filho, J.; Gregory, P.; Leão, E.R.; et al. Prevalence of burnout syndrome in clinical nurses at a hospital of excellence. Int. Arch. Med. 2014, 7, 22. Available online: https://www.ncbi.nlm.nih.gov/pmc/ articles/PMC4031323/ (accessed on 26 June 2019). [CrossRef]

10. Aiken, L.H. Hospital Nurse Staffing and Patient Mortality, Nurse Burnout, and Job Dissatisfaction. JAMA 2002, 288, 1987. [CrossRef]

11. Maslachi, C.; Jackson, S.E.; Leiter, M.P. MBI Maslach Burnout Inventory; CPP Incorporated: Sunnyvale, CA, USA, 1996. 
12. Halbesleben, J.R.B.; Demerouti, E. The construct validity of an alternative measure of burnout: Investigating the English translation of the Oldenburg Burnout Inventory. Work Stress 2005, 19, 208-220. [CrossRef]

13. Wu, S.; Zhu, W.; Wang, Z.; Wang, M.; Lan, Y. Relationship between burnout and occupational stress among nurses in China. J. Adv. Nurs. 2007, 59, 233-239. [CrossRef] [PubMed]

14. Leiter, M.P.; Price, S.L.; Laschinger, H.K.S. Generational differences in distress, attitudes and incivility among nurses. J. Nurs. Manag. 2010, 18, 970-980. [CrossRef] [PubMed]

15. Green, D.E.; Walkey, F.H.; Taylor, A.J. The three-factor structure of the Maslach Burnout Inventory: A multicultural, multinational confirmatory study. J. Soc. Behav. Personal. 1991, 6, 453.

16. Loera, B.; Converso, D.; Viotti, S. Evaluating the Psychometric Properties of the Maslach Burnout Inventory-Human Services Survey (MBI-HSS) among Italian Nurses: How Many Factors Must a Researcher Consider? PLoS ONE 2014, 9. [CrossRef]

17. Li, X.; Guan, L.; Chang, H.; Zhang, B. Core Self-Evaluation and Burnout among Nurses: The Mediating Role of Coping Styles. PLoS ONE 2014, 9. [CrossRef]

18. Yao, Y.; Yao, W.; Wang, W.; Li, H.; Lan, Y. Investigation of risk factors of psychological acceptance and burnout syndrome among nurses in China. Int. J. Nurs. Pract. 2013. [CrossRef]

19. Ohue, T.; Moriyama, M.; Nakaya, T. Examination of a cognitive model of stress, burnout, and intention to resign for Japanese nurses. Jpn. J. Nurs. Sci. 2010, 8, 76-86. [CrossRef]

20. Lasebikan, V.O.; Oyetunde, M.O. Burnout among Nurses in a Nigerian General Hospital: Prevalence and Associated Factors. ISRN Nurs. 2012. [CrossRef]

21. Embriaco, N.; Papazian, L.; Kentish-Barnes, N.; Pochard, F.; Azoulay, E. Burnout syndrome among critical care healthcare workers. Curr. Opin. Crit. Care 2007, 13, 482-488. [CrossRef]

22. Al-Turki, H.A.; Al-Turki, R.A.; Al-Dardas, H.A.; Al-Gazal, M.R.; Al-Maghrabi, G.H.; Al-Enizi, N.H.; Ghareeb, B.A. Burnout syndrome among multinational nurses working in Saudi Arabia. Ann. Afr. Med. 2010, 9, 226. [CrossRef] [PubMed]

23. Xie, Z.; Wang, A.; Chen, B. Nurse burnout and its association with occupational stress in a cross-sectional study in Shanghai. J. Adv. Nurs. 2011, 67, 1537-1546. [CrossRef] [PubMed]

24. Agha, A.; Mordy, A.; Anwar, E.; Saleh, N.; Rashid, I.; Saeed, M. Burnout among middle-grade doctors of tertiary care hospital in Saudi Arabia. Work 2015, 51, 839-847. [CrossRef] [PubMed]

25. Ang, S.Y.; Dhaliwal, S.S.; Ayre, T.C.; Uthaman, T.; Fong, K.Y.; Tien, C.E.; Zhou, H.; Della, P. Demographics and personality factors associated with burnout among nurses in a Singapore tertiary hospital. BioMed. Res. Int. 2016. [CrossRef]

26. Freeborn, D.K. Satisfaction, commitment, and psychological well-being among HMO physicians. West. J. Med. 2001, 174, 13-18. [CrossRef]

(C) 2019 by the authors. Licensee MDPI, Basel, Switzerland. This article is an open access article distributed under the terms and conditions of the Creative Commons Attribution (CC BY) license (http://creativecommons.org/licenses/by/4.0/). 